$16^{\text {th }}$ International Congress of Metrology, 10012 (2013)

DOI: $10.1051 /$ metrology/201310012

(c) Owned by the authors, published by EDP Sciences, 2013

\title{
THE INFLUENCE OF TEMPERATURE AND CO2 IN EXHALED BREATH
}

\section{L'INFLUENCE DE LA TEMPÉRATURE ET DE CO2 DANS L'AIR EXPIRÉ}

Mirela-Adelaida Anghel and Prof. Fănel Iacobescu

Romanian Bureau of Legal Metrology, 11, Vitan-Bârzeşti, Bucharest, Romania

\begin{abstract}
Breath alcohol analyzers are widely accepted as legal measuring instruments used for determination of the mass concentration of alcohol in exhaled breath. The paper focuses on the following issues: configuration of experimental system; the assurance of traceability at the highest standards; the influence of $\mathrm{CO} 2$ and on the influence of the exhaled breath temperature when the human body's temperature increases up to 38,39 or, in extreme conditions, up to $40^{\circ} \mathrm{C}$.
\end{abstract}

Résumé. Ethylomètres sont largement acceptées comme des instruments de mesure légales utilisées pour la détermination de la concentration massique d'alcool dans l'air expiré. Le document met l'accent sur les points suivants: configuration du système expérimental; l'assurance de la traçabilité des étalons; l'influence de $\mathrm{CO} 2$ et l'influence de la température de l'air expiré lorsque la température du corps humain augmente jusqu'à 38,39 ou, dans des conditions extrêmes, jusqu'à $40^{\circ} \mathrm{C}$..

\section{INTRODUCTION}

It is well-known that on the one hand alcohol is a stimulant but on the other hand, from a medical point of view, it is a cellular toxin. After drinking, the alcohol diffuses through the stomach and the small intestine walls, passing via the capillaries into the bloodstream. Due to the ethanol property of being volatile a certain quantity of alcohol, proportional with blood alcohol concentration, transfers from blood to lung alveoli (in the same way that $\mathrm{CO}_{2}$ goes from blood to the lung alveoli) in order to be eliminated from human body. In accordance with Henry's law, a fixed equilibrium is generated between the mass concentration of alcohol in the blood in the lungs (BAC) and the mass concentration of alcohol in the air in the lungs (BrAC), as a result of diffusion compensation process, as illustrated into the figure 1 .
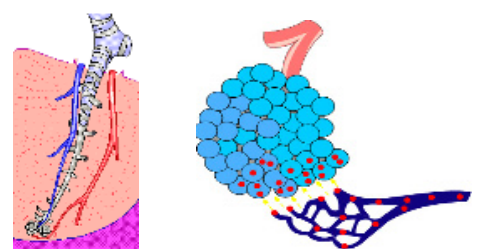

Figure 1- Illustrated exchange of alcohol within the lungs according with the Henry's law

\section{EXPERIMENTAL SYSTEM}

The experimental system [1], presented in figure 2 [2] consists of:

- CRMs-LNE

Table 1 - CRMs certified by LNE

\begin{tabular}{|c|c|c|c|}
\hline \multicolumn{2}{|c|}{$\begin{array}{c}\text { Mass concentration } \\
\text { of alcohol in } \\
\text { standard solution }\end{array}$} & \multicolumn{2}{|c|}{$\begin{array}{c}\text { Mass concentration } \\
\text { of alcohol in } \\
\text { simulated breath }\end{array}$} \\
\hline $\begin{array}{c}\gamma_{\text {eth }} \\
{[\gamma / \mathrm{L}]}\end{array}$ & $\begin{array}{c}U_{\text {eth }} \\
{[\mathrm{g} / \mathrm{L}]}\end{array}$ & $\gamma_{\text {air }}[\mathrm{mg} / \mathrm{L}]$ & $\begin{array}{c}U_{\text {air }} \\
{[\mathrm{mg} / \mathrm{L}]}\end{array}$ \\
\hline 0.2573 & 0.0005 & 0.1000 & 0.0033 \\
\hline 0.5146 & 0.0006 & 0.1995 & 0.0033 \\
\hline 0.9005 & 0.0011 & 0.3500 & 0.0033 \\
\hline 1.0292 & 0.0012 & 0.3990 & 0.0033 \\
\hline 1.8011 & 0.0021 & 0.6980 & 0.0033 \\
\hline 2.4444 & 0.0028 & 0.9500 & 0.0033 \\
\hline 3.8595 & 0.0044 & 1.5000 & 0.0033 \\
\hline
\end{tabular}

- Alcocal Simulator System - a new wet Bath Simulator System with Depletion Compensation having the traceability to PTB Germany and "3 bubble-train" Mark II, according to OIML R 126

\footnotetext{
a Corresponding author: mirela.a.anghel@gmail.com; office $a$ brml.ro
} 
- Alcotest 9510 breath analyser, which is using a dual IR \& EC technology, having the traceability to LNE France.

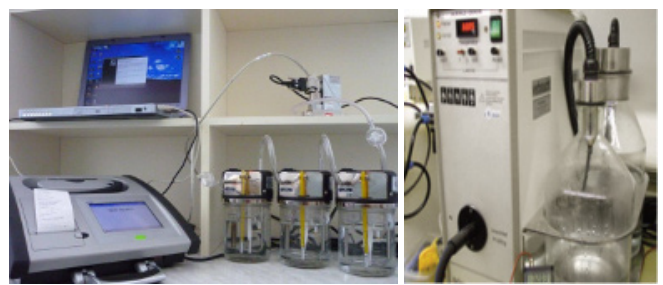

Figure 2- The calibration simulator system

\section{THE INFLUENCE OF CO2}

The major components of the inhaled air is Earth's atmosphere: $\mathrm{N}_{2}-78 \%, \mathrm{O}_{2}-21 \%$ and $\mathrm{CO}_{2}-0.04 \%$; while the air humans breathe out has a different concentration: $\mathrm{N}_{2} 78$ $\%, \mathrm{O}_{2}-16 \%$ and $\mathrm{CO}_{2}-4.5 \%$. This major difference in $\mathrm{O} 2$ and $\mathrm{CO} 2$ concentrations depends on human's internal metabolic process and must be correctly evaluated in order to avoid errors which might occur when reporting the final result associated with corresponding uncertainty.

In order to assure the traceability and to have a very good understanding regarding the influence of $\mathrm{CO} 2$ in the measurements of mass concentration of alcohol in exhaled breath also, a number of 7 standard solutions with traceability to LNE France [7], [8] and a recipient under the pressure having a volume fraction of $5.0 \% \mathrm{CO} 2$ in synthetic air was used. A number of 10 measurements were made with and without $\mathrm{CO}_{2}$ [9]. The results are presented in table 2 and the graphycal representation is presented in figure 3 .

Table 2. The influence of $\mathrm{CO}_{2}$ at different mass concentrations of alcohol in exhaled breath [10]

\begin{tabular}{|c|c|c|c|}
\hline $\begin{array}{c}\gamma_{\mathrm{CRM}} \\
{[\mathrm{mg} / \mathrm{L}]}\end{array}$ & $\begin{array}{c}\gamma_{\mathrm{m}} \\
\left(-\mathrm{CO}_{2}\right) \\
{[\mathrm{mg} / \mathrm{L}]}\end{array}$ & $\begin{array}{c}\gamma_{\mathrm{m}} \\
\left(+\mathrm{CO}_{2}\right) \\
{[\mathrm{mg} / \mathrm{L}]}\end{array}$ & $\begin{array}{c}\mathrm{RSD} \\
{[\%]}\end{array}$ \\
\hline 0.1000 & 0.0884 & 0.1003 & $\mathbf{1 1 . 9 0}$ \\
\hline 0.1995 & 0.1915 & 0.2044 & $\mathbf{6 . 4 7}$ \\
\hline 0.3500 & 0.3421 & 0.3585 & $\mathbf{4 . 6 9}$ \\
\hline 0.3990 & 0.3947 & 0.4108 & $\mathbf{4 . 0 4}$ \\
\hline 0.6980 & 0.7048 & 0.7217 & $\mathbf{2 . 4 2}$ \\
\hline 0.9500 & 0.9564 & 0.9740 & $\mathbf{1 . 8 5}$ \\
\hline .5000 & 1.5420 & 1.5575 & $\mathbf{1 . 0 3}$ \\
\hline
\end{tabular}

\section{THE INFLUENCE OF TEMPERATURE}

The experimental studies made on health human beings showed that the temperature human breath varies between 33.3 and $34.4{ }^{0} \mathrm{C}$. The temperature of a healthy human being is about 37 degrees Celsius while the exhaled breath temperature varies around 34 degrees Celsius. Taking into consideration that the body's temperature can have in
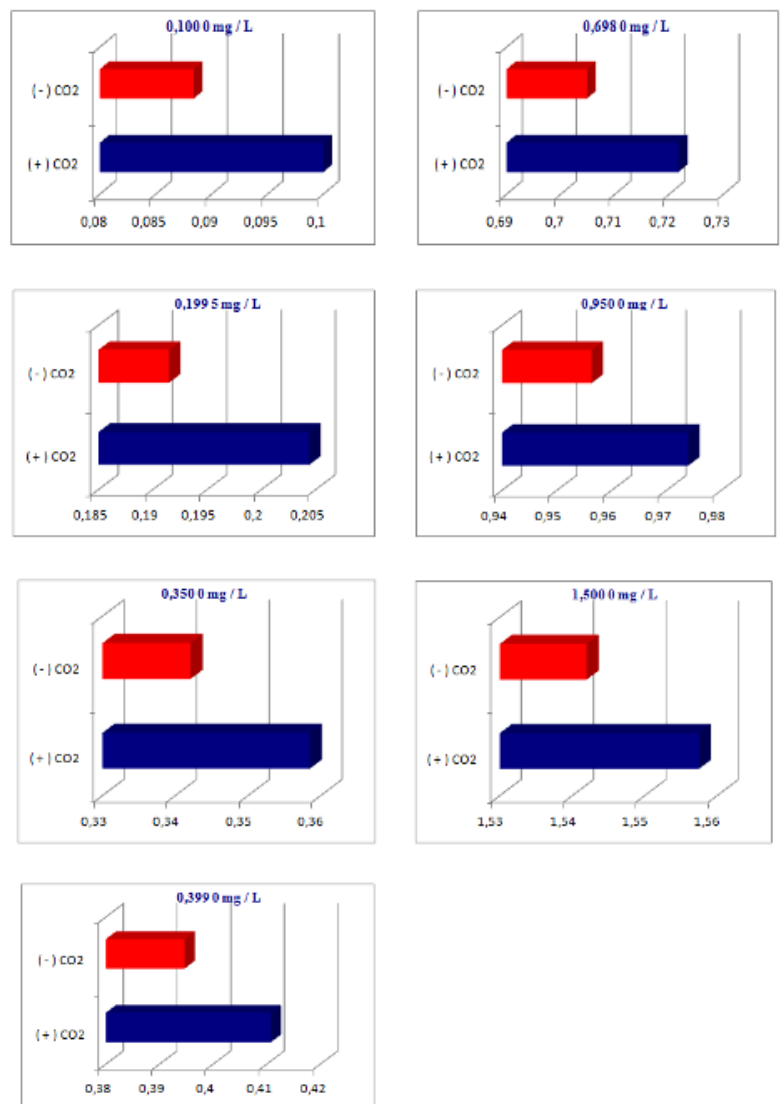

Figure 3-Influence of $\mathrm{CO}_{2}$-grafical representation

extreme conditions about 40 degrees Celsius which means that a difference of about 3 degrees Celsius was found between the air temperature [4], [5], [6] from alveoli and the breath exhaled temperature. For this study a number of 20 repeated measurements were made for 6 levels of CRMs at $32,33,34,35$ and $36{ }^{\circ} \mathrm{C}$ and a prediction for 37 ${ }^{0} \mathrm{C}$ [3] was calculated. The results are presented in tables 3 and 4 
Table 3. The mass concentration of alcohol with $1{ }^{0} \mathrm{C} \& 2{ }^{0} \mathrm{C}$ variation of breath temperature. Prediction for $3{ }^{0} \mathrm{C}[3]$

\begin{tabular}{|c|c|c|c|c|c|c|c|}
\hline CRM & {$[\mathrm{g} / \mathrm{L}]$} & 0.2573 & 0.5146 & 0.9005 & 1.0292 & 1.8011 & 2.4444 \\
\hline$\gamma_{-} \mathbf{C R M}_{34}$ & {$[\mathrm{mg} / \mathrm{L}]$} & 0.1000 & 0.1995 & 0.3500 & 0.3990 & 0.6980 & 0.9500 \\
\hline $\mathbf{T}_{34}$ & {$\left[{ }^{0} \mathrm{C}\right]$} & 33.94 & 34.08 & 34.04 & 34.01 & 33.92 & 33.99 \\
\hline$\gamma_{34}$ & {$[\mathrm{mg} / \mathrm{L}]$} & 0.0865 & 0.1913 & 0.3441 & 0.3936 & 0.6990 & 0.9558 \\
\hline $\mathbf{T}_{35}$ & {$\left[{ }^{0} \mathrm{C}\right]$} & 34.98 & 35.02 & 35.30 & 34.97 & 35.08 & 35.12 \\
\hline$\gamma_{35}$ & {$[\mathrm{mg} / \mathrm{L}]$} & 0.0943 & 0.2054 & 0.3749 & 0.4222 & 0.7563 & 1.0318 \\
\hline $\mathbf{T}_{36}$ & {$\left[{ }^{0} \mathrm{C}\right]$} & 36.21 & 36.06 & 36.06 & 36.03 & 36.46 & 36.23 \\
\hline$\gamma_{36}$ & {$[\mathrm{mg} / \mathrm{L}]$} & 0.0986 & 0.2201 & 0.3949 & 0.4513 & 0.8289 & 1.0967 \\
\hline $\mathbf{T}_{35}-\mathbf{T}_{34}$ & {$\left[{ }^{0} \mathrm{C}\right]$} & 1.04 & 0.95 & 1.26 & 0.96 & 1.16 & 1.13 \\
\hline$\gamma_{35}-\gamma_{34}$ & {$[\mathrm{mg} / \mathrm{L}]$} & 0.0078 & 0.0141 & 0.0308 & 0.0286 & 0.0553 & 0.0761 \\
\hline$\Delta \gamma, 1^{0} \mathrm{C}$ more & [\%] & 0.75 & 1.48 & 2.44 & 2.99 & 4.76 & 6.75 \\
\hline $\mathbf{T}_{36}-\mathbf{T}_{34}$ & {$\left[{ }^{0} \mathrm{C}\right]$} & 2,27 & 2.02 & 2.02 & 1.90 & 2.54 & 2.24 \\
\hline$\gamma_{36}-\gamma_{34}$ & {$[\mathrm{mg} / \mathrm{L}]$} & 0.0121 & 0.0288 & 0.0508 & 0.0578 & 0.1299 & 0.1410 \\
\hline$\Delta \gamma, 2^{\circ} \mathrm{C}$ more & {$[\%]$} & 1.07 & 2.86 & 5.01 & 6.08 & 10.21 & 12.57 \\
\hline Prediction $\gamma_{37}$ & {$[\mathrm{mg} / \mathrm{L}]$} & 0.1049 & 0.2293 & 0.4182 & 0.4758 & 0.8739 & 1.1671 \\
\hline$\Delta \gamma, 3^{0} \mathrm{C}$ more & {$[\%]$} & 1.84 & 3.80 & 7.41 & 8.22 & 17.49 & 21.14 \\
\hline
\end{tabular}
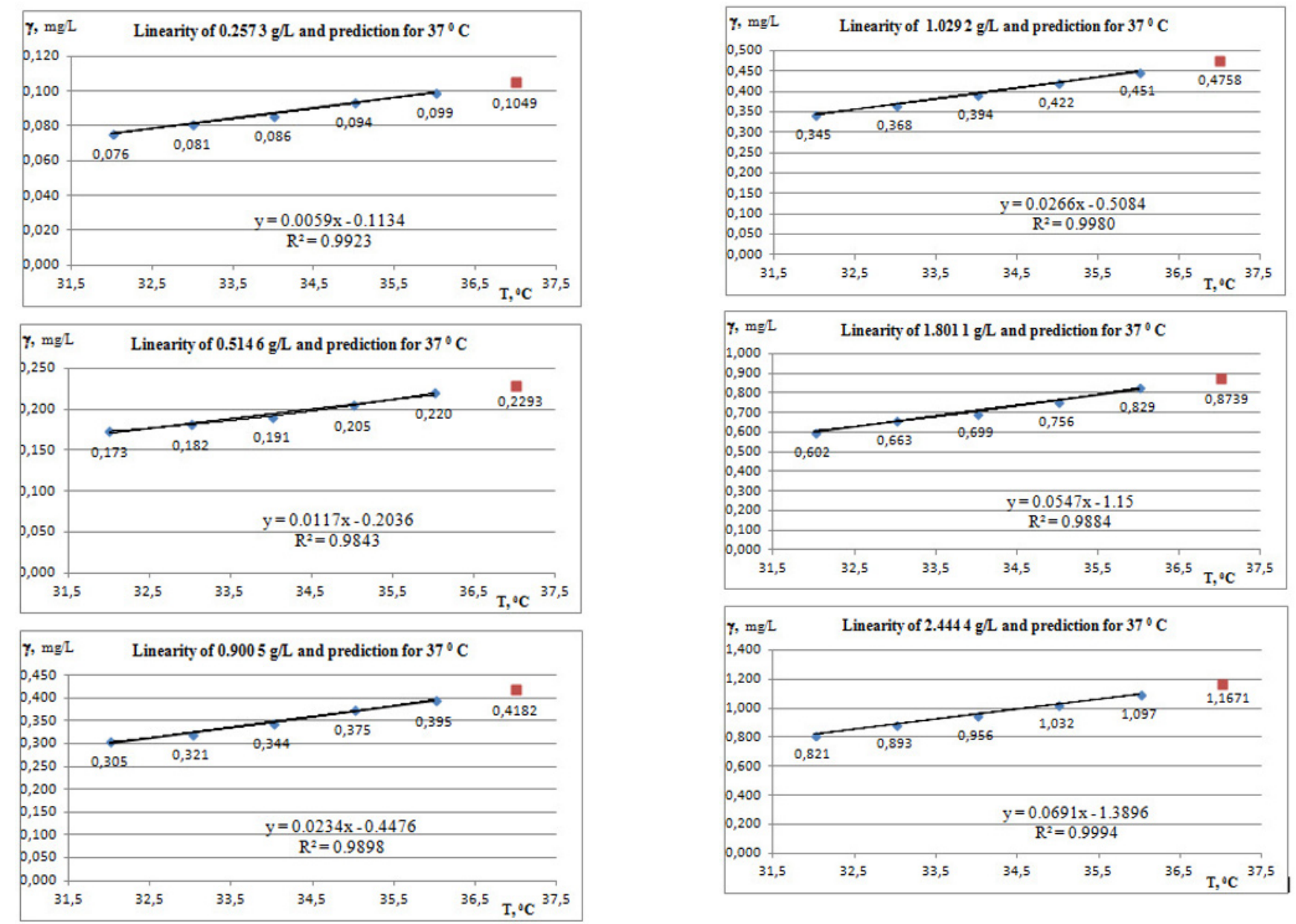

Figure 4-Prediction for $37^{0} \mathrm{C}$ 


\section{CONCLUSIONS}

The experiments conducted for the purpose of this article have been performed with the following equipments: CRMs prepared by gravimetric method, AlcoCal wet simulator system with depletion compensation of alcohol and Alcotest 9510 configured with a dual IR \& EC technology. The measurements results, presented in tables $2-3$ and figures $3-4$, prove our good capabilities in the field of mass concentration of alcohol in exhaled breath. Table 2 and figure 3 demonstrate the fact that is mandatory to use a mixture of air and $\mathrm{CO}_{2}$ in simulator system or to take into consideration its contribution to the final result of measurements. The temperature of a healthy human being is about 37 degrees Celsius, while the exhaled breath temperature varies around 34 degrees Celsius. Taking into consideration a difference of about 3 degrees of exhaled breath temperature, figure 4 is focused on the influence of the exhaled breath temperature when the human body's temperature increases up to 38,39 or, in extreme conditions, up to 40 degrees Celsius.

The measurement results shows that a variation of temperature by 1 degree Celsius produces a variation of alcohol mass concentration, corresponding to each CRM, with the following percentages: $0.75 \% ; 1.48 \% ; 2.44 \%$; $2.99 \% ; 4.76 \% ; 6.75 \%$; while, the variation of temperature by 2 Celsius degrees results in a variation of alcohol mass concentration as follows: $1.07 \%$; $2.86 \%$; $5.01 \%$; $6.08 \% ; 10.21 \% ; 12.57 \%$.

The results have been extended for $37{ }^{\circ} \mathrm{C}$ using prediction tools. The temperature of a healthy human being is about 37 degrees Celsius while the exhaled breath temperature

\section{REFERENCES}

\section{[1] Evidential breath analyzers, OIML R 126.}

[2] M. Anghel, Metrology of Mass Concentration of Alcohol in Exhaled Breath, Printech, București, 2009.

[3] M. Anghel, "Statistical Inference of Breath Alcohol Concentration Measurement", EPE Conference, Iasi, Romania, pp. 816-819, 2012.

[4] M.Anghel and F. Iacobescu, "Uncertainty Budget for Mass Concentration of Exhaled Breath Alcohol", Congress of Metrology, Paris, France, 2011.

[5] M. Anghel, "Traceability of Mass Concentration of Exhaled Breath Alcohol Measurements and Associated varies around 34 degrees Celsius. That means that a difference of about 3 degrees Celsius was found between the air temperature from alveoli and the breath exhaled temperature. Taking into consideration that the body's temperature can have in extreme conditions about 40 degrees Celsius, the experiment has been conducted for 5 different temperatures. Using the measurement results, the calibration curves were drawn for each of these 5 temperatures and a prediction for 37 degrees Celsius was calculated. The measurement results are presented in figure 4 . The predictions of mass concentrations of alcohol for an exhaled breath temperature about 37 degrees Celsius have been: $0.1049 \mathrm{mg} / \mathrm{L}$ (for $0.2573 \mathrm{~g} / \mathrm{L}$ ); $0.2293 \mathrm{mg} / \mathrm{L}$ (for $0.5146 \mathrm{~g} / \mathrm{L}$ ); $0.4182 \mathrm{mg} / \mathrm{L}$ (for $0.9005 \mathrm{~g} / \mathrm{L}$ ); 0.4758 $\mathrm{mg} / \mathrm{L}$ (for $1.0292 \mathrm{~g} / \mathrm{L}$ ); $0.8739 \mathrm{mg} / \mathrm{L}$ (for $1.8011 \mathrm{~g} / \mathrm{L}$ ) and $1.1672 \mathrm{mg} / \mathrm{L}$ (for $2.4444 \mathrm{~g} / \mathrm{L}$ ). For each CRM used, the predicted value clearly fitted into the corresponding calibration curve.

A variation of exhaled breath temperature by 3 degrees Celsius, from 34 to 37 degrees Celsius, generates a significant variation in mass concentration of alcohol with: $1.84 \%$ (for $0.2573 \mathrm{~g} / \mathrm{L}$ ); $3.80 \%$ (for $0.5146 \mathrm{~g} / \mathrm{L}$ ); $7.41 \%$ (for $0.9005 \mathrm{~g} / \mathrm{L}$ ); $8.22 \%$ (for $1.0292 \mathrm{~g} / \mathrm{L}$ ); $17.49 \%$ (for $1.8011 \mathrm{~g} / \mathrm{L}$ ) and $21.14 \%$ (for $2.4444 \mathrm{~g} / \mathrm{L}$ ).

The linear equations for the variation of mass alcohol concentration with temperature are presented. The value of the correlation factor, close to 1 for all mass alcohol concentrations, proves a dependency of mass alcohol concentration on the temperature of the subject tested with these modern, non-invasive analysis methods used by breath alcohol analyser.

Uncertainty Evaluation in Romania" OIML Bulletin 1, pp. $13-21,2009$.

[6] M. Anghel and F. Iacobescu, "Quality Assurance of Breath Alcohol Measurements", IMEKO Conference, Busan-Korea, 2012.

[7] Evaluation of measurement data - An Introduction to the Guide to the Expression of Uncertainty in Measurement and Related Documents, BIPM 104, 2009.

[8] Quantifying Uncertainty in Analytical Measurement, Eurachem / CITAC Guide $3^{\text {rd }}$ edition, 2012.

[9] M. Anghel and F. Iacobescu, "The influence of $\mathrm{CO}_{2}$ in the Measurements of Mass Concentration of Alcohol in Exhaled Breath Using a Dual IR\&EC Technology", EPE Conference Iaşi, Romania, pp. 805-809, 2012. 